\title{
Erdheim chester disease: A case report and review of the literature
}

\author{
Rémie Philippe Elia, ATALLAH Adnan, AKIKI Béatrice, WAKED Hani, ZEIDAN Marwan, MAKAREM Jawad, \\ AFTIMOS Georges \\ Lebanese University; Institut National de Pathologie, Baabda, Republic of Lebanon
}

Received: June 9, 2020

DOI: $10.5430 /$ crcp.v7n1p22
Accepted: August 5, 2020

URL: https://doi.org/10.5430/crcp.v7n1p22

\begin{abstract}
Erdheim Chester disease is a rare form of non-Langerhans histiocytosis with frequent BRAF V600E mutations. It is mainly characterized by multifocal osteosclerotic bone lesions with or without systemic involvement. The histologic image is consistent with a histiocytic proliferation of foamy cells in a polymorphic background. The main difference from the Langerhans histiocytosis is the immune profile with mainly S100, CD1a, and langerin negative. The overall prognosis is dependent on extraskeletal involvement. Herein, we present a typical presentation of Erdheim Chester disease with a review of the literature.
\end{abstract}

Key Words: Erdheim chester disease, non-Langerhans histiocytosis, BRAF mutations

\section{CASE REPORT}

We report the case of a 72-year-old man who presented to the orthopedic clinics for back pain and fatigue of several weeks duration, post-fall. An associated weight loss of $12 \mathrm{~kg}$ in the past year is noted. His past medical history revealed a controlled type 2 diabetes, a multinodular thyroid goiter, and splenomegaly. The back pain was localized and continuous throughout the day. He was admitted to undergo investigations to rule out any malignant process. Upon admission, despite the described bone involvement, the physical examination was normal without significant alterations. His laboratory tests showed anemia with a hemoglobin of 10.

Following his initial evaluation, a 64 multidetector computed tomography scan was performed and it showed mild splenomegaly, a $5 \mathrm{~mm}$ fat-rich left adrenal adenoma and a thickening of the rectal wall most pronounced on the right side. The two lytic lesions, shown in Figure 1, were noted in the right iliac wing and vertebral body of L4 measuring respectively $4.2 \mathrm{~cm} \times 3 \mathrm{~cm} \times 1.3 \mathrm{~cm}$ and $3 \mathrm{~cm} \times 2.5 \mathrm{~cm} \times$ $2 \mathrm{~cm}$. The vertebral body of $\mathrm{L} 1$ shows sclerosis with wedge fracture and anterior loss of height estimated at 35\%. The overall findings raised the possibility of bone metastasis with pathological fracture involving the L1 vertebral body.

A CT guided bone biopsy was performed from the lytic lesion seen in the right iliac bone and the specimen was sent to the pathology laboratory.

The histopathologic findings revealed an expansion of the marrow by a proliferation of foamy macrophages intermingled with multinucleated giant cells, Touton type, shown in Figure 2. Numerous polymorphs and eosinophils were also seen. The immunohistochemical study revealed a strong expression of CD163 in the foamy cells, represented in Figure 3. The antibodies anti - CDla and anti - S100 were negative. A final diagnosis of Erdheim-Chester disease was emitted with a warranted clinical correlation.

*Correspondence: Rémie Philippe Elia; Email: remie_elia@hotmail.com; Address: Lebanese University, Republic of Lebanon. 
The mutation on codon 600 of exon 15 of the BRAF gene was detected.
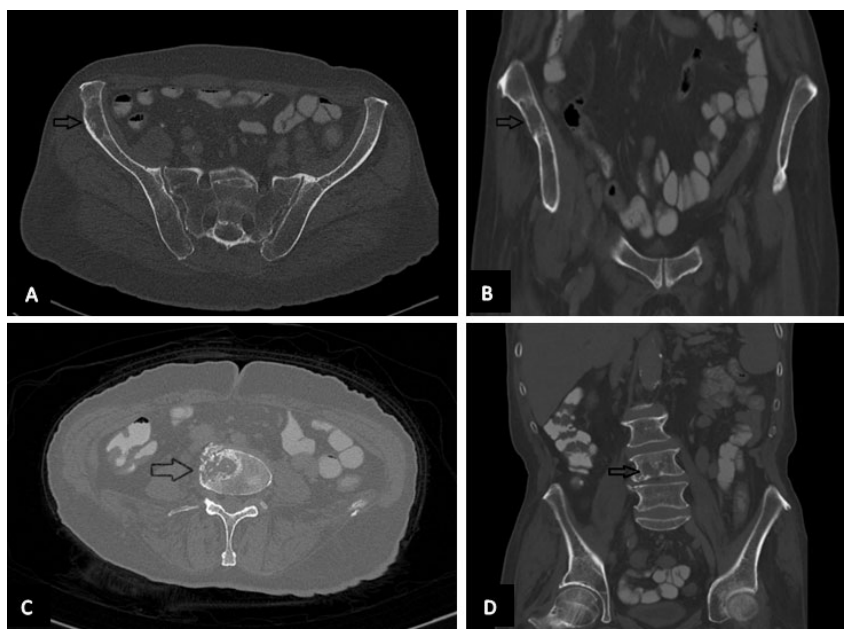

Figure 1. CT-scan showing lytic bone lesion pointed by the black arrow: A. Axial view showing a right iliac wing lytic lesion; B. Coronal view showing the lytic lesion in the right iliac wing; C. Axial view showing lytic lesion at the level of L4 vertebral body; D. Coronal view of the lytic bone lesion at the level of L4 vertebral body

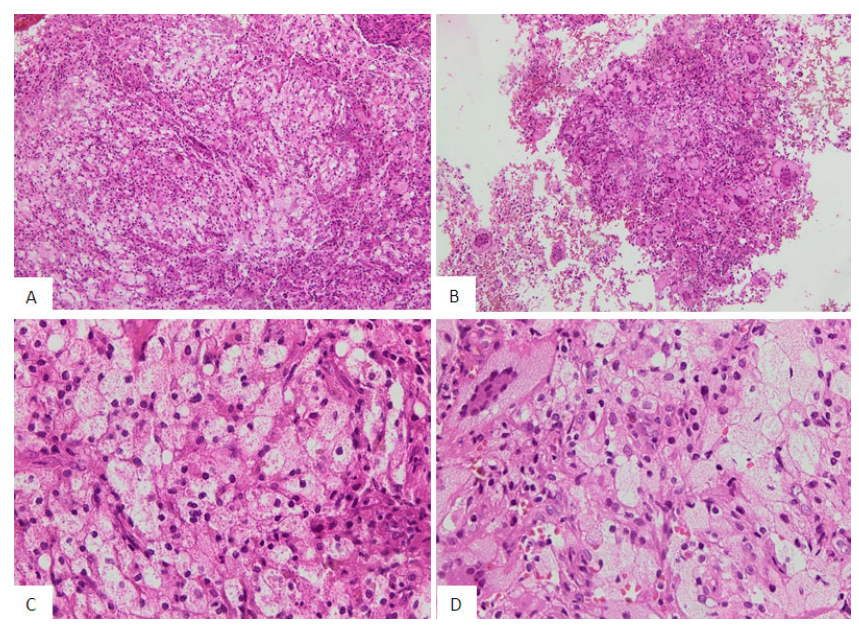

Figure 2. Hematoxylin and Eosin stain. A. 10x magnification showing histiocytic proliferation; B. 10x magnification showing the presence of Touton type giant cells; C. 40x magnification showing proliferation of foamy macrophages; D- 40x magnification showing foamy macrophages intermingled with giant cells.

\section{Discussion}

Erdheim Erdheim Chester disease (ECD), is a rare, systemic inflammatory disease. It is most commonly characterized by multifocal osteosclerotic lesions of long bones by a non-
Langerhans form of histiocytosis, with or without extraskeletal involvement. The first two reported cases were described by Jakob Erdheim and William Chester in 1930 as "lipoid granulomatosis". ${ }^{[1]}$

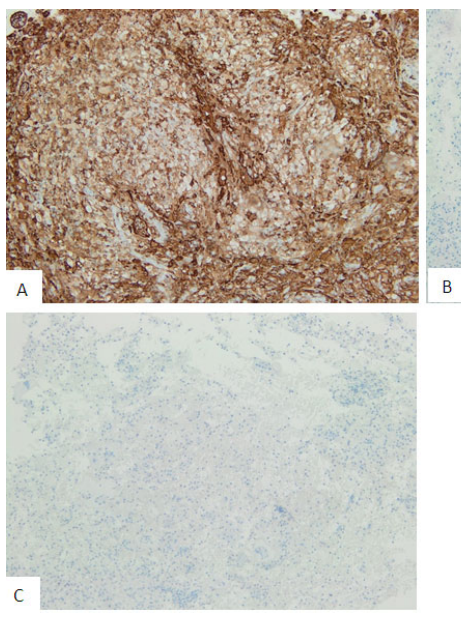

Figure 3. Special immunohistochemistry. A. Strong expression of CD163 in foamy cells; B. Negative S100 staining; C. Negative CD1a staining

ECD is an exceedingly rare and largely overlooked diagnosis. Therefore, the overall incidence rate is unknown. ${ }^{[2,3]}$ The mean age at diagnosis is 55 to 60 years of age, with a slight male predominance. ${ }^{[3]}$

The clinical presentation is broad and varies from one patient to another. It depends largely on the extent and distribution of the disease, which may range from asymptomatic bone lesions to multisystemic, life-threatening forms with poor prognosis. More than $95 \%$ of ECD patients have skeletal involvement. The commonest form is a bilateral and symmetric cortical osteosclerosis of the diaphyseal and metaphyseal regions, sparing the epiphyses portion of the long bones of the extremities, seen mainly in the distal femur, proximal tibia and fibula. These radiological characteristics are highly suggestive of the disease. ${ }^{[3-5]}$ In contrast, the Langerhans cell histiocytosis ( $\mathrm{LCH})$ involves commonly the calvarium, facial bones, proximal limbs, and scapula. ${ }^{[6]}$ Other clinical scenarios can also be identified: exophthalmos, diabetes insipidus, interstitial lung disease, bilateral adrenal enlargement, retroperitoneal fibrosis with perirenal and/or ureteral obstruction, renal impairment, testis infiltration, central nervous system (CNS), and/or cardiovascular involvements. ${ }^{[5,7]}$

The ECD diagnosis is based on the combination of the clinical characteristics, imaging features, and histological confirmation. ${ }^{[8]}$ Tissue biopsy is necessary for histological confirmation and molecular profiling for therapeutic purposes. ${ }^{[10]}$ 
The involved tissue is infiltrated by large histiocytes with single small nuclei and xanthomatous cytoplasm, admixed with multinucleated histiocytes with a central ring of nuclei (Touton cells). Different degrees of fibrosis with reactive small lymphocytes, plasma cells, and neutrophils are also seen. The ECD histiocytes express the common markers of the macrophage lineage (CD14, CD68, and CD163), along those of dendritic and interdigitating dendritic cells (factor XIIII and fascin). However, these abnormal histiocytes lack the Langerhans cell's markers (S100, CD1a, and langerin). Some histiocytes may present a focal expression of S100. $20 \%$ of ECD patients may have mixed histiocytosis with simultaneous Langerhans cell histiocytosis lesions, which can be even identified in the same biopsy. ${ }^{[9,10]}$ Moreover, the ECD histiocytes share the same morphological and immunohistochemical profile of the juvenile xanthogranuloma (JXG). Therefore, it has been postulated that ECD is a variant of a non-cutaneous JXG. ${ }^{[11]}$

The molecular profile of Erdheim Chester disease demonstrated a high prevalence of somatic BRAF V600 mutations, which result in the activation of the well-known oncogenic MAPK pathway. ${ }^{[12]}$ This prevalence goes as high as $54 \%$ in one study. ${ }^{[13]}$ Moreover, the mutational BRAF V600E testing is mainly influenced by the histiocytic count present in the tissue biopsy. ${ }^{[14]}$

Based on these results, the recommended treatment for multisystem BRAF V600-mutant ECD with life-threatening conditions such as cardiac or neurologic involvement is a BRAF inhibitor. BRAF-inhibitor or immunosuppressive/cytotoxic therapy is the treatment of choice for BRAF V600 - mutant without life-threatening conditions. However, for ECD patients without BRAF V600 mutation, it is recommended to continue Next-generation Sequencing (NGS) to identify other MAPK-ERK pathway alterations. ${ }^{[9,15]}$

\section{Conclusion}

In conclusion, ECD is a rare entity of non-Langerhans cell histiocytosis of adulthood with frequent BRAF V600 mutations. It is characterized by excessive production and accumulation of histiocytes in multiple tissues and organs. The diagnosis remains challenging and should be suspected in the presence of multisystem involvement.

\section{CONFlicts OF InTEREST Disclosure}

We declare that we have no conflict interests.

\section{REFERENCES}

[1] Chester W. Uber Lipoidgranulomatose. Virchows Arch Pathol Anat 1930; 279: 561-602. https://doi.org/10.1007/BF01942684

[2] Haroche J, Arnaud L, Amoura Z. Erdheim-Chester disease. Curr Opin Rheumatol. 2012; 24: 53-9. PMid:22089098. https ://doi. org/10.1097/BOR.0b013e32834d861d

[3] Veyssier-Belot C, Cacoub P, Caparros-Lefebvre D, et al. ErdheimChester disease. Clinical and radiologic characteristics of 59 cases. Medicine (Baltimore). 1996; 75: 157-69. PMid:8965684. https: //doi.org/10.1097/00005792-199605000-00005

[4] Murray D, Marshall M, England E, et al. Erdheim-Chester disease. Clin Radiol. 2001; 56: 481-484. PMid:11428798. https: //doi.org/10.1053/crad.2001.0681

[5] Arnaud L, Hervier B, Neel A, et al. CNS involvement and treatment with interferon-alpha are independent prognostic factors in Erdheim-Chester disease: a multicenter survival analysis of 53 patients. Blood. 2011; 117: 2778-2782. PMid:21239701. https : //doi.org/10.1182/blood-2010-06-294108

[6] Wilejto M, Abla O. Langerhans cell histiocytosis and ErdheimChester disease. Curr Opin Rheumatol. 2012; 24(1): 90-96. PMid:22157416. https://doi.org/10.1097/BOR.0b013e3283 $4 \mathrm{db} 53 \mathrm{e}$

[7] Haroche J, Amoura Z, Dion E, et al. Cardiovascular involvement, an overlooked feature of Erdheim-Chester disease: report of 6 new cases and a literature review. Medicine (Baltimore). 2004; 83: 371-392. PMid:15525849. https://doi.org/10.1097/01.md.00001453 68.17934 .91

[8] Munoz J, Janku F, Cohen PR, et al. Erdheim-Chester disease: characteristics and management. Mayo Clin Proc. 2014; 89: 985-996.
PMid:24814521. https://doi.org/10.1016/j . mayocp. 2014. 01.023

[9] Goyal G, Heaney ML, Collin M, et al. Erdheim-Chester disease: consensus recommendations for the evaluation, diagnosis, and treatment in the molecular era. Blood. 2020; 135: 1929-45. PMid:32187362. https://doi.org/10.1182/blood.2019003507

[10] Emile JF, Abla O, Fraitag S, et al. Revised classification of histiocytoses and neoplasms of the macrophage-dendritic cell lineges. Blood. 2016; 127: 2672-81. PMid:26966089. https://doi.org/10.118 2/blood-2016-01-690636

[11] Breuil V, Brocq O, Pellegrino C, et al. Erdheim-Chester disease: typical radiological bone features for a rare xanthogranulomatosis. Ann Rheum Dis. 2002; 61(3): 199-200. PMid:11830422. https: //doi.org/10.1136/ard.61.3.199

[12] Davies H, Bignell GR, Cox C, et al. Mutations of the BRAF gene in human cancer. Nature. 2002; 417(6892): 949-954. PMid:12068308. https://doi.org/10.1038/nature00766

[13] Haroche J, Charlotte F, Arnaud L, et al. High prevalence of BRAF V600E mutations in Erdheim-Chester disease but not in other non-Langerhans cell histiocytoses. Blood. 2012; 120(13): 27002703. PMid:22879539. https://doi org/10.1182/blood-201 2-05- 430140

[14] Cangi MG, Biavasco R, Cavalli G, et al. BRAFV600E-mutation is invariably present and associated to oncogene-induced senescence in Erdheim-Chester disease [published online ahead of print Mar 26, 2014]. Ann Rheum Dis.

[15] Nayak L. From inflammation to cancer: entering a new frontier in the management of Erdheim-Chester disease. Neuro-oncology. 2020; 22(7): 905-906. PMid:32343812. https://doi .org/10.1093/ne uonc/noaa110

ISSN 2331-2726 E-ISSN 2331-2734 